\title{
Gene aberrations of RRM1 and RRM2B and outcome of advanced breast cancer after treatment with docetaxel with or without gemcitabine
}

Charlotte LT Jørgensen ${ }^{1 *}$, Bent Ejlertsen ${ }^{2}$, Karsten D Bjerre ${ }^{2}$, Eva Balslev ${ }^{1}$, Dorte L Nielsen ${ }^{3}$ and Kirsten V Nielsen ${ }^{4}$

\begin{abstract}
Background: The purpose of the present study was to retrospectively evaluate whether copy number changes of the genes encoding the ribonucleotide reductase subunit M1 (RRM1) and/or subunit M2B (RRM2B) predict sensitivity to gemcitabine administered in combination with docetaxel compared to single agent docetaxel in advanced breast cancer patients.

Methods: Primary tumor samples from patients randomly assigned to gemcitabine plus docetaxel or docetaxel alone were analyzed for RRM1 and RRM2B copy number changes using Fluorescence In Situ Hybridization (FISH) technology with probes covering respectively RRM1 at $11 \mathrm{p} 15.5$ and a reference probe covering the centromere of chromosome 11 (CEN-11), and RRM2B at 8q22.3 and a reference probe covering the centromere of chromosome 8 (CEN-8). The assays were validated in a material of 60 normal breast samples. Time to progression (TTP) was the primary endpoint. Overall survival (OS) and response rate (RR) were secondary endpoints. Associations between RRM1/CEN-11 and/or RRM2B/CEN-8 ratios and time-to-event endpoints were analyzed by unadjusted and adjusted Cox proportional hazards regression models. Heterogeneity of treatment effects on TTP and OS according to gene status were investigated by subgroup analyses, and the Wald test was applied. All statistical tests were two-sided.

Results: FISH analysis for both RRM1 and RRM2B was successful in 251 patients. RRM1 and RRM2B aberrations (deletions and amplifications) were observed in $15.9 \%$ and $13.6 \%$ of patients, respectively. RRM1 aberrations were associated with a decreased OS in the time interval 1.5-7.4 years (hazard ratio $=1.72,95 \%$ confidence interval $=1.05-2.79, \mathrm{P}=0.03$ ). $R R M 2 B$ aberrations alone or in combination with $R R M 1$ aberrations had no prognostic impact in terms of TTP or OS. RR was not different by gene status. No significant differences were detected in TTP or OS within subgroups according to gene status and chemotherapy regimen.

Conclusions: This study demonstrated the presence of RRM1 and RRM2B copy number changes in primary breast tumor specimens. Nevertheless, we found no support of the hypothesis that aberrations of RRM1 or $R R M 2 B$, neither individually nor in combination, are associated with an altered clinical outcome following chemotherapy with gemcitabine in combination with docetaxel compared to docetaxel alone in advanced breast cancer patients.
\end{abstract}

Keywords: Docetaxel, FISH, Gemcitabine, Gene aberrations, Metastatic breast cancer, Ribonucleotide reductase, RRM1, RRM2B

\footnotetext{
* Correspondence: charlotte.levin.tykjaer.joergensen@regionh.dk

'Department of Pathology, Herlev University Hospital, Copenhagen, Denmark

Full list of author information is available at the end of the article
} 


\section{Background}

Ribonucleotide reductase (RNR) catalyzes the formation of deoxyribonucleotides, thus is a key enzyme during DNA synthesis and repair [1,2], and is the specific cellular target of gemcitabine [3]. Mammalian cells enclose three non-identical subunits of RNR: one homodimeric large subunit (RRM1) carrying the catalytic site, and two variants of a homodimeric small subunit (RRM2 and RRM2B) containing a tyrosyl free radical essential for catalysis [1,2]. As a nucleoside analogue, gemcitabine is intracellularly phosphorylated into the active metabolite gemcitabine diphosphate, which is recognized by RNR as a normal substrate and reacts with the substrate-binding catalytic site of the RRM1 subunit thereby inactivating the enzyme [3-5]. Preclinical research has indicated that increased tumor expression of RRM1 is the major determinant of resistance to gemcitabine [6], and two cell line studies have demonstrated an association between gemcitabine resistance and gene amplification of $R R M 1$ [7,8]. In addition, low/negative RRM1 mRNA and protein levels have been reported to correlate significantly with higher response rate and a better prognosis in lung cancer patients treated with gemcitabine-based chemotherapy, and in pancreatic and biliary cancer patients treated with gemcitabine alone [6,9]. However, there are reports, including a prospectively conducted phase III clinical trial, of RRM1 either not being significantly associated or possibly oppositely associated with survival in lung cancer patients receiving a gemcitabine-containing regimen [10-13]. A possible association between mRNA and protein expression of RRM2 or the RRM2B subunit and the effect of gemcitabine is less well studied and has not been addressed in properly sized randomized trials and results from pilot trials are inconsistent [10,14-18].

Thus, an unambiguous association has not been established between mRNA and protein expression of RNR and benefit from gemcitabine. The underlying copy number changes of the genes encoding the subunits of RNR may be determined more reproducible. To address this issue, gene copy number alterations of the enzyme subunits as determined by Fluorescence In Situ Hybridization (FISH) technology were evaluated in archival primary tumor samples from patients with locally advanced and metastatic breast cancer randomized to docetaxel alone (D) versus gemcitabine plus docetaxel (GD) [19]. Secondarily, the overall prognostic impact of RNR gene copy number variation in these patients receiving chemotherapy was investigated. Furthermore, as chromosomal instability and copy number alterations have previously been reported to be more prone to accumulate in highly proliferative subtypes (i.e. non-luminal A) $[20,21]$, we analyzed the genomic landscape of RNR gene copy number changes in relation to PAM50 classified intrinsic subtypes (Jørgensen et al. manuscript provisionally accepted for publication) to investigate subtype specific patterns.

\section{Methods}

\section{The patient study cohort}

The Danish Breast Cancer Cooperative Group (DBCG) phase III multicenter 0102 trial randomized 337 women with advanced breast cancer to D versus GD. The trial has been described in detail previously [19]. Patients were randomly assigned to $\mathrm{D}\left(100 \mathrm{mg} / \mathrm{m}^{2}\right)$ day 1 , or G $\left(1000 \mathrm{mg} / \mathrm{m}^{2}\right)$ days 1 and 8 plus $\mathrm{D}\left(75 \mathrm{mg} / \mathrm{m}^{2}\right)$ day 8 , every 3 weeks. Prior chemotherapy with a non-taxane regimen was allowed either adjuvant or as first-line. The study was conducted in accordance with the Declaration of Helsinki, and all patients gave their signed informed consent prior to study entry. DBCG prepared the original protocol as well as the biomarker supplement, and the Danish National Committee on Biomedical Research Ethics approved the original protocol in addition to the add-on (KF-02-045-01 and KF-12-315632/H-KF-02045-01) before activation.

\section{Specimen collection}

Formalin-fixed, paraffin-embedded (FFPE) primary tumor blocks from participating patients were retrospectively collected from the archives of pathology departments throughout hospitals of Denmark. All samples were analyzed as tissue microarrays (TMAs), except six samples analyzed as whole sections because of small tumor size. Areas from the periphery of invasive tumor in donor blocks were identified on haematoxylin-eosin stained sections and TMAs were designed in the same manner as described previously [22]. From available and suitable blocks, $2.0 \mathrm{~mm}$ core TMAs were constructed by means of a TMA builder (Beecher Instrument ATA-27) by a histopathology skilled biologist (CLTJ) under supervision of a pathologist (EB). Consecutive $3 \mu \mathrm{m}$ sections from each TMA block and the six whole tissue blocks were cut for processing of FISH.

\section{Assay validation cohort}

For assay validation we analyzed the RNR candidate gene copy number variation in 60 TMA samples of normal breast gland tissue as previously described in Nielsen et al. 2011 [23].

\section{Pilot study}

A pilot study was conducted to evaluate the existence of copy number changes of the genes encoding the subunits of RNR (RRM1, RRM2, RRM2B) as determined by FISH in primary tumor samples from 49 of the 337 advanced breast cancer patients treated with D versus GD [19]. Genetic aberrations were observed regarding $R R M 1$ and $R R M 2 B$ (data not shown). Despite the fact that a relationship between the expression of the RRM2 subunit and 
gemcitabine has also been suggested, no copy number changes were found regarding RRM2 during the pilot study (data not shown), and further evaluation of the entire cohort concerned RRM1 and RRM2B copy number changes only.

\section{RRM1 and RRM2B FISH assay development}

The FISH assays were developed based on bacterial artificial chromosome (BAC) DNA fluorescent probes covering the sequence of the $R R M 1$ gene at $11 \mathrm{p} 15.5$ (BAC clones RP11-23F23 and RP11-982G19) and the RRM2B gene at 8q22.3 (BAC clone RP11-318G5), respectively. As reference, centromeric Peptide Nucleic Acid (PNA) probes specific for chromosome 11 (CEN-11) and 8 (CEN-8) were applied. The RRM1 and RRM2B targeted BAC clones were labeled with Texas Red fluorochrome by Nick translation. Centromere targeted reference probes were based on a mixture of PNA oligoes labeled with fluorescein isothiocyanate. As blocking agent a mixture of alu PNA oligoes was used.

\section{FISH analysis}

FISH analysis was performed on samples from tumor tissue and normal tissue using Dako Histology FISH accessory kit (K5599, Dako A/S, Glostrup, Denmark) according to the manufacturer's instructions and as described previously [23]. Evaluation of slides was done according to the topoisomerase II-alpha (TOP2A) FISH scoring guidelines (from Dako K5333 USA package insert, $1^{\text {st }}$ edition 2008.01.18). Sufficient nuclei were included until a total of 60 red gene probe signals were counted along with the green reference probe signals in the corresponding nuclei. The ratio was calculated as the number of signals for the gene probe divided by the number of signals for the centromere reference probe. A case was considered to be amplified if the gene/centromere ratio was $2: 1$ or greater and deleted if the ratio was below $0.8: 1$, and otherwise normal. For explorative analysis, gene amplification was defined by a ratio of $1.5: 1$ or greater and gene deletion by a ratio below 0.9:1.

\section{Statistical analysis}

For statistical analysis, data were dichotomized into overall genetic changes (amplification and deletion) and no genetic changes of RRM1 or RRM $2 B$, respectively. Combined genetic status of $R R M 1$ and $R R M 2 B$ was dichotomized as $2 \mathrm{R}$ aberrant (amplification and deletion of one or both genes) and otherwise as $2 \mathrm{R}$ normal (normal copy number status of both genes).

Associations between gene status and prognostic and demographic variables of the main study [19] including PAM50 intrinsic subtype (Jørgensen et al. manuscript provisionally accepted for publication) were assessed. Associations between gene status and categorical variables (regimen, hormone receptor status, human epidermal growth factor receptor 2 (HER2) status, type of metastatic site, stage of disease, previous chemo-, hormonal-, and radio-therapy, and PAM50 intrinsic subtype) were evaluated by Fisher's exact test, whereas associations between gene status and ordinal and interval variables (ECOG performance status, age at randomization, number of metastatic sites, and disease-free interval) were evaluated by the Wilcoxon rank-sum test.

Time to progression (TTP) was the primary endpoint for the original trial as well as for this biomarker sub-study [19], and overall survival (OS) and response rate (RR) were secondary endpoints. TTP was measured from random assignment to date of documented progression with censoring at date of last visit or at date of death. OS was calculated from date of random assignment to date of death with censoring for surviving patients at last visit date. Time-to-event endpoints (TTP and OS) were estimated by the Kaplan-Meier method, and association with gene status was assessed by the log-rank test. Analyses of gene status were done unadjusted and adjusted for preselected covariates in multivariate Cox proportional hazards models. The preselected covariates were those found to be significant in the previous analysis of the main study [19] including treatment regimen, disease type (visceral vs nonvisceral), stage of disease, performance status, and number of metastatic sites, in addition to PAM50 intrinsic subtype (Jørgensen et al. manuscript provisionally accepted for publication). The adjusted model was further stratified for previous chemotherapy [19]. The assumption of proportional hazards was assessed by Schoenfeld residuals. Subgroup analyses were done to assess whether treatment effects on TTP and OS varied according to gene status or the levels of preselected covariates. The multivariate Cox proportional hazards model was extended by one interaction term at a time and the interaction terms were tested using the Wald test.

RR was evaluated for patients with measurable disease. The overall RR was defined as a complete or partial response according to RECIST criteria, version 1.0. RRs were compared by using Fisher's exact test.

Statistical analyses were conducted using the SAS version 9.2 software package (SAS Institute, Cary, NC, USA). All statistical tests were two sided, and $\mathrm{P}<0.05$ considered statistically significant. Reporting Recommendations for Tumor Marker Prognostic Studies (REMARK) were adhered where applicable [24]. The design of the study is prospective-retrospective as described in Simon et al. [25].

\section{Results}

For the present study FFPE primary tumor tissue was available from 278 (82\%) of the 337 patients enrolled in the intention to treat population (Figure 1). FISH analysis for $R R M 1$ and $R R M 2 B$ was successful in 261 (94\%) and 


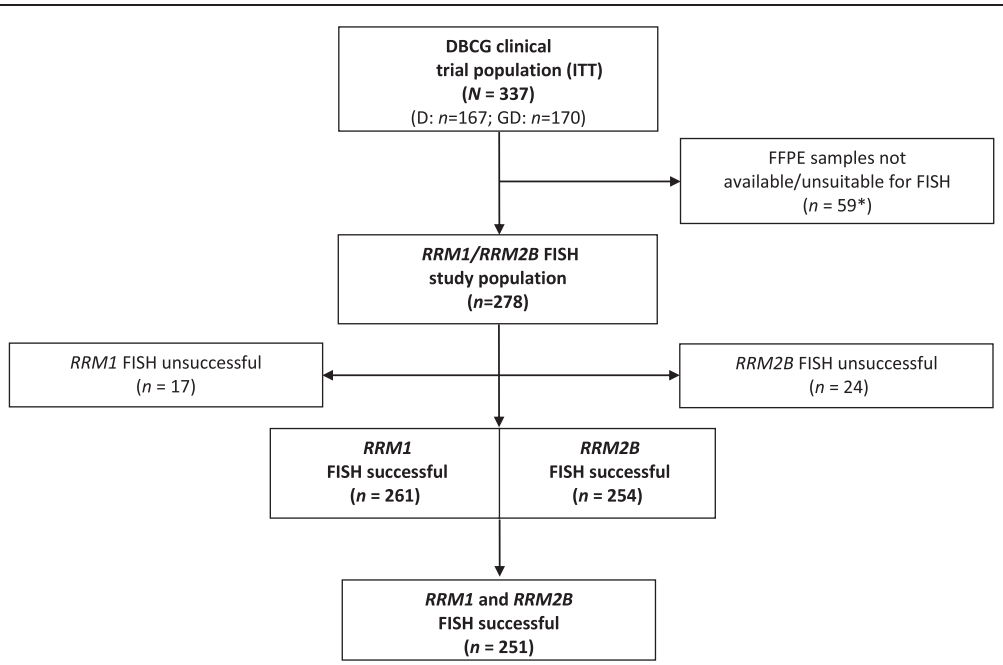

Figure 1 Flow diagram of the presented study. *Patients were withdrawn for one of the following reasons: archival tissue not available $(n=36)$, no tumor cells in available samples $(n=8)$, only needle biopsies available $(n=12)$, tissue samples available from metastasis only $(n=3)$. Abbreviation: D, docetaxel; DBCG, Danish Breast Cancer Cooperative Group; FFPE, formalin-fixed, paraffin-embedded; GD, gemcitabine plus docetaxel; FISH, fluorescence in situ hybridization; RRM1, ribonucleotide reductase M1 subunit; RRM2B, ribonucleotide reductase M2B subunit.

254 (91\%) of the 278 patients, respectively. $251 / 278$ patients $(90 \%)$ had measurements of both genes and were included in the prespecified prospective-retrospective analysis.

Tumor tissue from patients who relapsed after primary mastectomy or breast conserving surgery was available from 229 (76\%) compared to 22 (65\%) from patients with locally advanced disease at diagnosis. As a consequence the 251 FISH assessable patients differed from the 86 non-assessable patients $(\mathrm{P}<0.05)$ with regard to prior $($ neo) adjuvant chemotherapy, adjuvant hormonal therapy, and adjuvant radiotherapy, but not for other assessed parameters (Additional file 1: Table S1).

The distribution of gene/centromere ratios are illustrated in Figure 2. RRM1/CEN-11 ratios were found in the range 0.13-3.35 (Figure 2A), and $R R M 2 B / C E N-8$ ratios in the range $0.43-7.33$ (Figure 2B). Among the 251 patients, 38 patients (15.1\%) had RRM1 deletions (Figure 3A) and 2 (0.8\%) had RRM1 amplifications, whereas 8 patients (3.2\%) had $R R M 2 B$ deletions and 26 (10.4\%) had RRM2B amplifications (Figure $3 B)$. A total of 7 patients $(2.8 \%)$ had an aberration of both genes (Table 1).

Patient and baseline characteristics according to RRM1, $R R M 2 B$, and $2 \mathrm{R}$ status were assessed. No association was found between $R R M 1$ and $R R M 2 B$ status, and $R R M 1$ status was not associated with any other factors (Additional file 2: Table S2). RRM2B status was significantly associated with median age at randomization $(\mathrm{P}=0.03)$, bone metastases $(\mathrm{P}=0.03)$, HER2 status $(\mathrm{P}=0.01)$, prior chemotherapy for locally advanced or metastatic disease $(\mathrm{P}=0.02)$ (Additional file 2: Table S2), and PAM50 subtype ( $\mathrm{P}=0.0004$ ) (Table 2 ). All $R R M 2 B$ aberrations except one were found in nonluminal A cancers (Table 2). The $2 \mathrm{R}$ status was significantly associated with median age at randomization $(\mathrm{P}=0.02)$, stage of disease $(\mathrm{P}=0.02)$, bone metastases $(\mathrm{P}=0.02)$, HER2 status $(\mathrm{P}=0.04)$ (Additional file 2: Table S2), and PAM50 subtype ( $\mathrm{P}=0.009)$ (Table 2 ).

RR did not differ significantly according to status of RRM1, RRM2B or 2R (Table 3). However, a non-significant trend of a better overall RR was seen in patients with $R R M 1$ aberrations (32\% RRM1 normal; 50\% RRM1 aberrant, $\mathrm{P}=0.08)$.

In Kaplan-Meier analyses, $R R M 1, R R M 2 B$ or $2 \mathrm{R}$ status were not significantly associated with TTP or OS (Figure 4). The Cox proportional hazards model for TTP and OS confirmed this result (Table 4). To meet the proportionality assumption of the Cox model, the OS model for RRM1 was separated according to short time (0-1.5 years) and long time prognosis (1.5-7.4 years). Patients with RRM1 aberrations tended to have a better OS in the time interval 0-1.5 years from randomization, though this difference was not statistically significant (hazard ratio $(\mathrm{HR})=0.59$, 95\% confidence interval $(\mathrm{CI})=0.34-1.03, \mathrm{P}=0.06)$. In contrary, RRM1 aberrations were significantly associated with a poorer OS in the time interval 1.5-7.4 years $(\mathrm{HR}=$ $1.67,95 \% \mathrm{CI}=1.06-2.62, \mathrm{P}=0.03)$. To test the independent value of $R R M 1, R R M 2 B$, and $2 \mathrm{R}$ status against standard clinical and pathologic factors, multivariable Cox models were constructed. RRM1 aberrations remained an independent prognostic factor with an impact on OS from 1.5-7.4 years from randomization $(\mathrm{HR}=1.72,95 \% \mathrm{CI}=$ 1.05-2.79, $\mathrm{P}=0.03$ ) (Table 4).

Treatment effect of GD versus D was comparable to the effect in the original study with regard to TTP (adjusted HR 0.56; 95\% CI, 0.40-0.79, P=0.001) and OS (HR 0.84; $95 \% \mathrm{CI}, 0.64-1.12, \mathrm{P}=0.23$ ) [19]. The subgroup analyses 


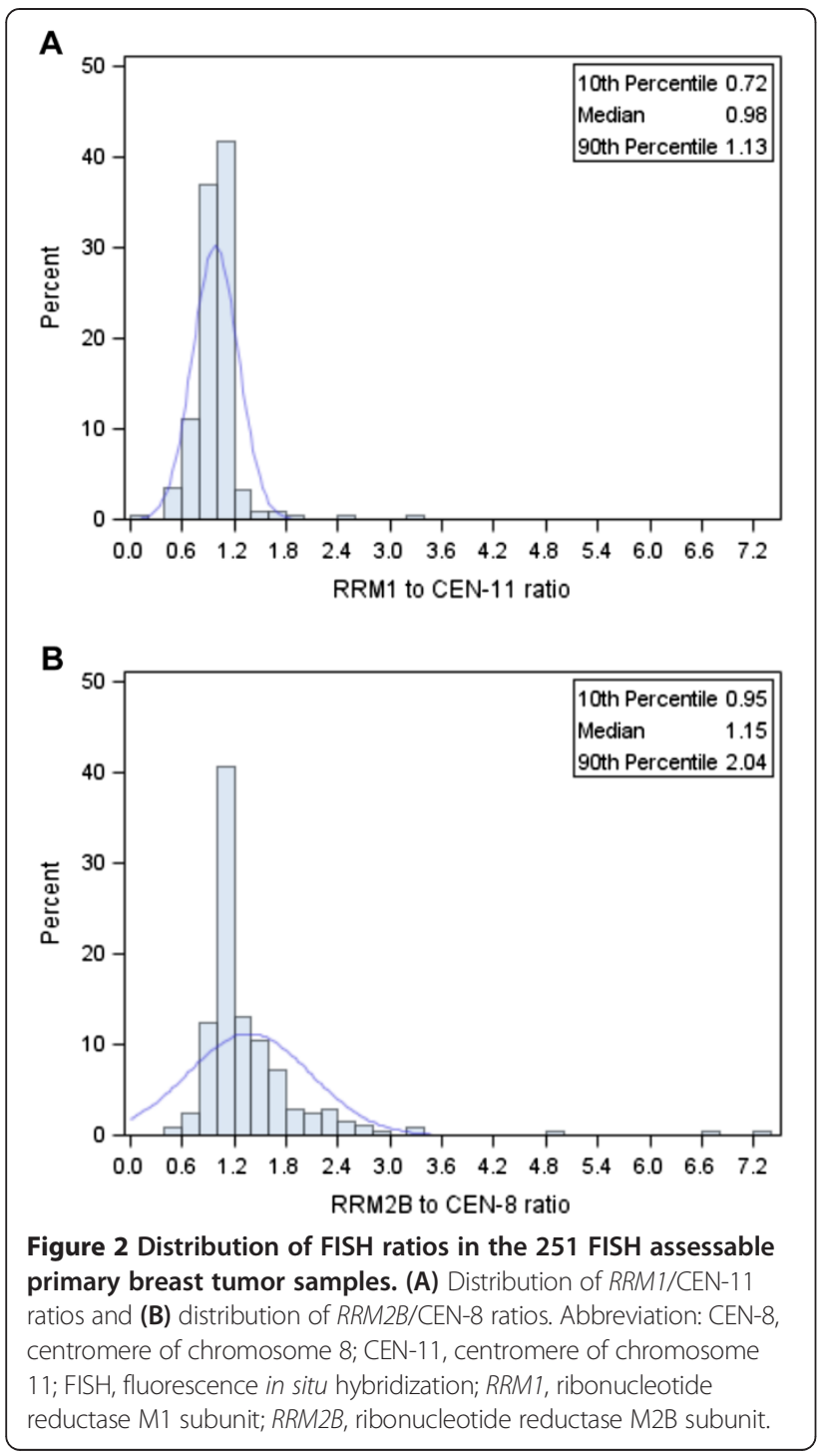

showed no treatment effect heterogeneity on the TTP and OS endpoints according to RRM1 (TTP, $\mathrm{P}_{\text {interaction }}=0.35$; OS, $\left.\mathrm{P}_{\text {interaction }}=0.50\right), R R M 2 B\left(\mathrm{TTP}, \mathrm{P}_{\text {interaction }}=0.60\right.$; OS, $\left.\mathrm{P}_{\text {interaction }}=0.63\right)$, or $2 \mathrm{R}\left(\mathrm{TTP}, \mathrm{P}_{\text {interaction }}=0.24\right.$; OS, $\mathrm{P}_{\text {interaction }}=0.82$ ).

The explorative definition of amplification and deletion cut-points resulted in a higher proportion of RRM1 and $R R M 2 B$ aberrations but did not alter the results overall (data not shown).

For assay validation 60 normal breast samples were analyzed for $R R M 1$ and $R R M 2 B$ gene copy number variation. Neither amplifications nor deletions were found. For each sample $60+$ events $(1$ event $=1 \mathrm{red} /$ gene signal) was evaluated, with an average of 37.25 and 36.78 nuclei for RRM1 and $R R M 2 B$, respectively. An average of 1.62 red signals representing the $R R M 1$ genes and 1.55 green signals representing the centromeric sequence were counted. The
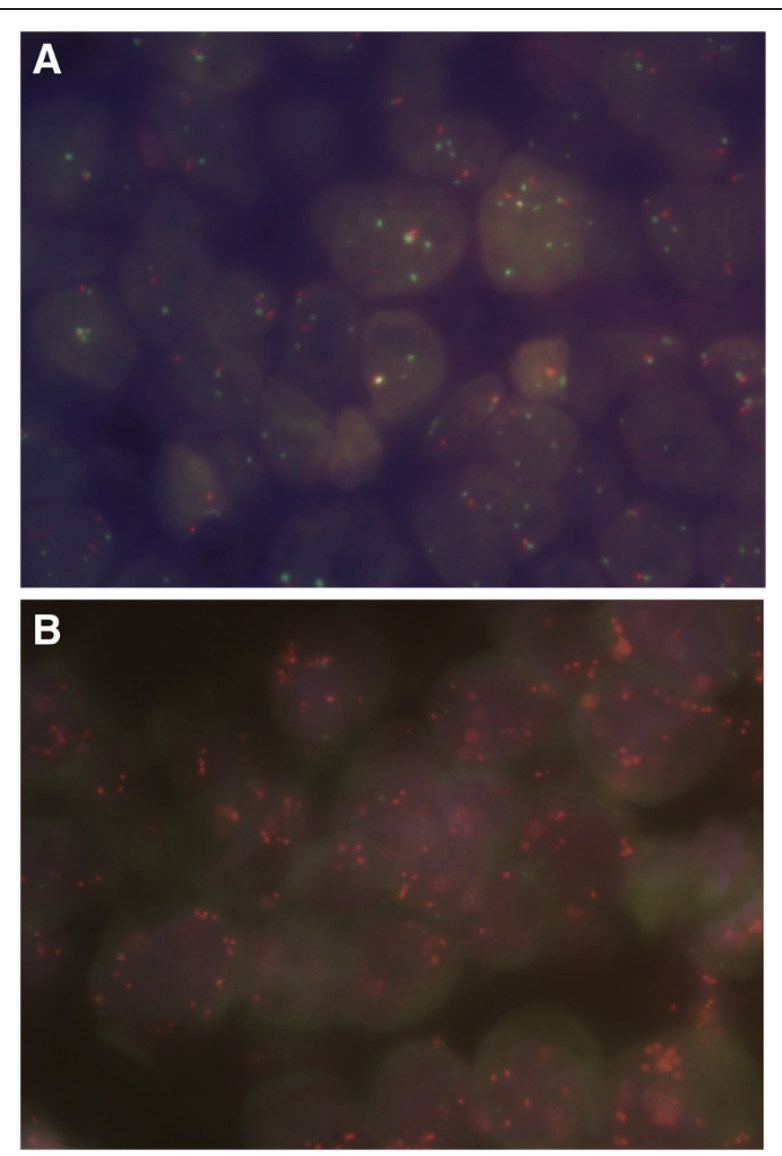

Figure 3 Photomicrographs demonstrating examples of $R R M 1$ and $R R M 2 B$ status in invasive breast tumors. Samples were analyzed by FISH using Texas Red (RRM1 or RRM2B) and fluorescein isothiocyanate (chromosome 11and 8) labeled probes (Leica DM microscope, $100 \times$ objective, oil emulsion). (A) Breast tumor with RRM1 gene deletion (FISH ratio < 0.8). (B) Breast tumor with RRM2B gene amplification (FISH ratio $\geq 2.0$ ). Abbreviation: FISH, fluorescence in situ hybridization; RRM1, ribonucleotide reductase $\mathrm{M} 1$ subunit; $R R M 2 B$, ribonucleotide reductase $M 2 B$ subunit.

RRM1/CEN-11 ratio varied from 0.92-1.20. An average of 1.64 red signals representing the $R R M 2 B$ genes and 1.55 green signals representing the centromeric sequence were counted. The RRM2B/CEN-8 ratio varied from 0.94-1.15.

Table 1 RRM1 and RRM2B status in 251 FISH assessable primary tumor samples from advanced breast cancer patients

\begin{tabular}{lcccc}
\hline \multicolumn{5}{c}{$\boldsymbol{R} \boldsymbol{R} \boldsymbol{M} \mathbf{1}$} \\
\hline $\boldsymbol{R}$ RM2B & Deletion & Normal & Amplification & Total \\
Deletion & 3 & 5 & 0 & $8(3.2 \%)$ \\
Normal & 31 & 184 & 2 & $217(86.4 \%)$ \\
Amplification & 4 & 22 & 0 & $26(10.4 \%)$ \\
& $38(15.1 \%)$ & $211(84.1 \%)$ & $2(0.8 \%)$ & 251 \\
\hline
\end{tabular}

Abbreviations: FISH fluorescence in situ hybridization, $R R M 1$ ribonucleotide reductase $M 1$ subunit, $R R M 2 B$ ribonucleotide reductase $M 2 B$ subunit. 
Table 2 Association between RRM1, RRM2B, and 2R status and PAM50 intrinsic subtype

\begin{tabular}{|c|c|c|c|c|c|c|c|c|c|c|c|c|c|c|c|}
\hline \multirow[t]{3}{*}{ Characteristics } & \multicolumn{5}{|c|}{ RRM1 } & \multicolumn{5}{|c|}{ RRM2B } & \multicolumn{5}{|c|}{$2 \mathrm{R}$} \\
\hline & \multicolumn{2}{|c|}{ Normal } & \multicolumn{2}{|c|}{ Aberrant } & \multirow[b]{2}{*}{$P^{a}$} & \multicolumn{2}{|c|}{ Normal } & \multicolumn{2}{|c|}{ Aberrant } & \multirow[b]{2}{*}{$P^{a}$} & \multicolumn{2}{|c|}{ Normal } & \multicolumn{2}{|c|}{ Aberrant } & \multirow[b]{2}{*}{$P^{a}$} \\
\hline & No. & $(\%)$ & No. & $(\%)$ & & No. & $(\%)$ & No. & $(\%)$ & & No. & $(\%)$ & No. & $(\%)$ & \\
\hline No. of patients & 211 & & 40 & & & 217 & & 34 & & & 184 & & 67 & & \\
\hline PAM50 ${ }^{b}$ & & & & & 0.38 & & & & & 0.0004 & & & & & 0.009 \\
\hline Luminal A & 63 & $(29.9)$ & 8 & $(20.0)$ & & 70 & $(32.3)$ & 1 & $(2.9)$ & & 62 & (33.7) & 9 & $(13.4)$ & \\
\hline Luminal B & 74 & $(35.1)$ & 15 & $(37.5)$ & & 75 & $(34.6)$ & 14 & $(41.2)$ & & 62 & (33.7) & 27 & $(40.3)$ & \\
\hline Basal-like & 32 & $(15.2)$ & 10 & $(25.0)$ & & 35 & $(16.1)$ & 7 & $(20.6)$ & & 27 & $(14.7)$ & 15 & $(22.4)$ & \\
\hline HER2-enriched & 37 & $(17.5)$ & 7 & $(17.5)$ & & 33 & $(15.2)$ & 11 & $(32.4)$ & & 29 & (15.8) & 15 & $(22.4)$ & \\
\hline Unknown & 5 & $(0.0)$ & 0 & $(0.0)$ & & 4 & (1.8) & 1 & (2.9) & & 4 & $(2.2)$ & 1 & (1.5) & \\
\hline
\end{tabular}

Abbreviations: $2 R$ aberration RRM1 and/or RRM2B aberrant, $2 R$ normal RRM1 and RRM2B both normal, HER2 human epidermal growth factor receptor 2, RRM1 ribonucleotide reductase $\mathrm{M} 1$ subunit, $R R M 2 B$ ribonucleotide reductase $M 2 B$ subunit.

${ }^{a}$ Fishers exact test, unknown values excluded from tests.

b PAM50: A 50-gene expression classifier that identifies the four major intrinsic subtypes of breast cancer known as the luminal A, luminal B, HER2-enriched and basal-like subtypes [26].

The ratios were distributed normally with a standard deviation of 0.05 (data not shown).

\section{Discussion}

This study demonstrated the existence of both deletions and amplifications of $R R M 1$ and $R R M 2 B$ in primary breast tumor samples, to our knowledge unprecedented in human tumor tissue but in agreement with the frequently observed somatic changes in the genome of breast cancer cell lines [27-29]. RRM1 aberrations were demonstrated to be a time-dependent prognostic factor with an impact on OS, and RRM $2 B$ aberrations were significantly associated with HER2 status and PAM50 subtype. In this study we found no heterogeneity of treatment effects according to $R R M 1$ or $R R M 2 B$ copy number status in terms of TTP or OS. Combining RRM1 and RRM2B aberrations did not add further information.
We found deletions to be the most frequent gene copy number variation in relation to $R R M 1$. The RRM1 gene resides at $11 \mathrm{p} 15.5$, a chromosomal region frequently associated with allelic loss in cancer [30,31] and agrees well with the RRM1 deletions frequently observed in this study. Low level of RRM1 in early-stage cancer patients treated with surgery only has been associated with reduced survival [32-35], whereas low RRM1 expression in gemcitabinetreated advanced cancer patients has been associated with improved survival $[6,9]$. The prognostic impact of RRM1 expression has not been confirmed in a randomized trial. A prospective randomized phase III trial by Reynolds et al (2009) [11] failed to demonstrate substantial difference in survival according to RRM1 levels in lung cancer patients treated with gemcitabine and carboplatin or gemcitabine monotherapy. The retrospective biomarker sub-study of another randomized phase III trial did not find a prognostic

Table 3 Best overall response ${ }^{a}$ by $R R M 1, R R M 2 B$, and $2 R$ status

\begin{tabular}{|c|c|c|c|c|c|c|c|c|c|c|c|c|}
\hline \multirow[t]{3}{*}{ Response } & \multicolumn{4}{|c|}{$R R M 1^{b}$} & \multicolumn{4}{|c|}{$R R M 2 B^{C}$} & \multicolumn{4}{|c|}{$2 \mathrm{R}^{d}$} \\
\hline & \multicolumn{2}{|c|}{ Normal } & \multicolumn{2}{|c|}{ Aberrant } & \multicolumn{2}{|c|}{ Normal } & \multicolumn{2}{|c|}{ Aberrant } & \multicolumn{2}{|c|}{ Normal } & \multicolumn{2}{|r|}{ Aberrant } \\
\hline & No. & $\overline{(\%)}$ & No. & $(\%)$ & No. & $(\%)$ & No. & $(\%)$ & No. & $(\%)$ & No. & (\%) \\
\hline $\mathrm{CR}$ & 3 & (2.3) & 2 & (7.1) & 3 & $(2.2)$ & 2 & (9.1) & 2 & (1.8) & 3 & (6.7) \\
\hline PR & 39 & $(29.8)$ & 12 & $(42.9)$ & 45 & $(32.8)$ & 6 & (27.3) & 36 & (31.6) & 15 & (33.3) \\
\hline Total responses & 42 & (32.0) & 14 & $(50.0)$ & 48 & $(35.0)$ & 8 & $(36.4)$ & 38 & (33.3) & 18 & $(40.0)$ \\
\hline $95 \% \mathrm{Cl}$ & & o 40.8) & & (30.7 to 69.4 ) & & o 43.7) & & o 59.3) & & ( 42.8) & & (25.7 to 55.7 ) \\
\hline SD & 63 & $(48.1)$ & 10 & (35.7) & 63 & $(46.0)$ & 10 & $(45.4)$ & 54 & $(47.4)$ & 19 & $(42.2)$ \\
\hline PD & 18 & $(13.7)$ & 1 & (3.6) & 15 & $(11.0)$ & 4 & $(18.2)$ & 14 & $(12.3)$ & 5 & $(11.1)$ \\
\hline Unknown & 8 & $(6.1)$ & 3 & $(10.7)$ & 11 & $(8.0)$ & 0 & $(0.0)$ & 8 & (7.0) & 3 & (6.7) \\
\hline Total & 131 & & 28 & & 137 & & 22 & & 114 & & 45 & \\
\hline
\end{tabular}

Abbreviations: $2 R$ aberration $R R M 1$ and/or $R R M 2 B$ aberrant, $2 R$ normal $R R M 1$ and $R R M 2 B$ both normal, $C l$ confidence interval, $C R$ complete response, $P D$ progressive disease, $P R$ partial response, $R R M 1$ ribonucleotide reductase $M 1$ subunit, $R R M 2 B$ ribonucleotide reductase M2B subunit, $S D$ stable disease.

${ }^{a}$ Response rate was evaluated for patients with the presence of at least one measurable lesion ( $\left.n=159\right)$ according to RECIST (Response Evaluation Criteria in Solid Tumors), version 1.0 .

${ }^{\mathrm{b}}$ Total responses, Fishers exact test $\mathrm{P}=0.08$.

${ }^{\mathrm{C}}$ Total responses, Fishers exact test $\mathrm{P}=1.00$

${ }^{\mathrm{d}}$ Total responses, Fishers exact test $\mathrm{P}=0.46$. 


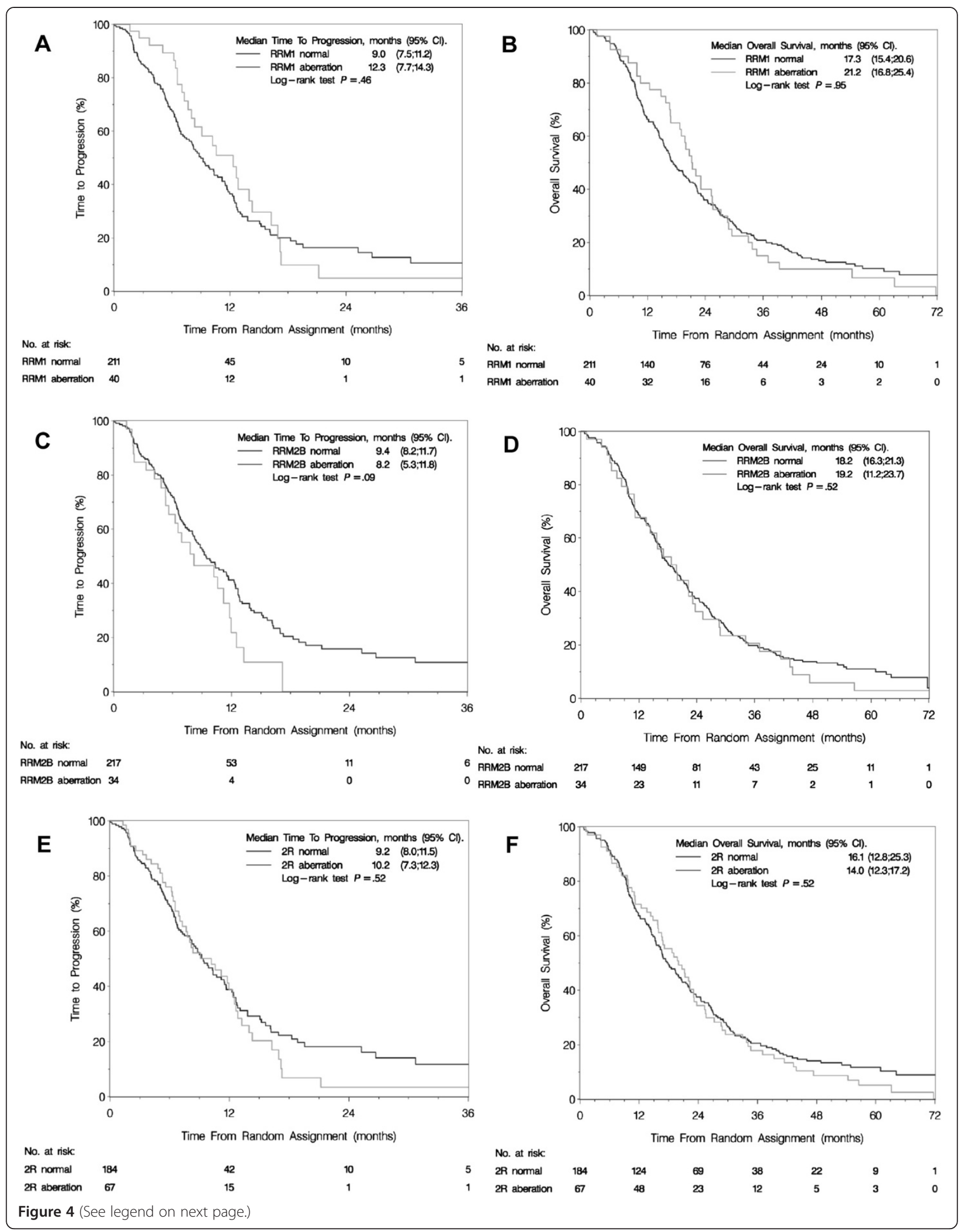


(See figure on previous page.)

Figure 4 Time to progression (164 events) and overall survival (228 events) of patients according to RRM1, RRM2B, and 2R status. (A) TTP according to RRM1 status. (B) OS according to RRM1 status. (C) TTP according to RRM2B status. (D) OS according to RRM2B status. (E) TTP according to RRM1 and RRM2B status combined. (F) OS according to RRM1 and RRM2B status combined. Abbreviations: 2R aberration, RRM1 and/or RRM2B aberrant; $2 \mathrm{R}$ normal, RRM1 and RRM2B both normal; $\mathrm{Cl}$, confidence interval; OS, overall survival; RRM1, ribonucleotide reductase $\mathrm{M} 1$ subunit; RRM2B, ribonucleotide reductase M2B subunit; TTP, time to progression.

impact of RRM1 protein expression in a subgroup of lung cancer patients randomly assigned to cisplatin-based chemotherapy including gemcitabine [13]. In the present study $R R M 1$ was demonstrated to be a time-dependent prognostic factor with an impact on OS 1.5-7.4 years from randomization $(\mathrm{HR}=1.72, \mathrm{P}=0.03) \cdot R R M 1$ aberrations were significantly associated with a decreased OS of the patients during this time interval. Though not statistically significant an inverse trend in OS was seen for patients with $R R M 1$ aberrations 0-1.5 years from randomization.

Table 4 Cox univariate and multivariate analysis for time to progression and overall survival

\begin{tabular}{|c|c|c|c|c|c|c|c|}
\hline \multirow[t]{2}{*}{ Risk factor } & \multirow[t]{2}{*}{$\mathbf{n}$} & \multicolumn{2}{|c|}{ Time to progression } & \multirow[t]{2}{*}{$\mathbf{P}$} & \multicolumn{2}{|c|}{ Overall survival } & \multirow[t]{2}{*}{$\mathbf{P}$} \\
\hline & & HR & $95 \% \mathrm{Cl}$ & & HR & $95 \% \mathrm{Cl}$ & \\
\hline \multicolumn{8}{|l|}{ Univariate analysis } \\
\hline \multicolumn{8}{|l|}{ RRM1 } \\
\hline Normal & 211 & 1.00 & Referent & & 1.00 & Referent & \\
\hline Aberration & 40 & 0.86 & $(0.57-1.29)$ & 0.46 & & & \\
\hline Aberration $0-1.5$ years* & & & & & 0.59 & $(0.34-1.03)$ & 0.06 \\
\hline Aberration $1.5-7.4$ years* & & & & & 1.67 & $(1.06-2.62)$ & 0.03 \\
\hline \multicolumn{8}{|l|}{$R R M 2 B$} \\
\hline Normal & 217 & 1.00 & Referent & & 1.00 & Referent & \\
\hline Aberration & 34 & 1.45 & $(0.94-2.25)$ & 0.09 & 1.13 & $(0.78-1.64)$ & 0.52 \\
\hline \multicolumn{8}{|l|}{$2 \mathrm{R}$} \\
\hline Normal & 184 & 1.00 & Referent & & 1.00 & Referent & \\
\hline Aberration & 67 & 1.25 & $(0.92-1.69)$ & 0.16 & & & \\
\hline Aberration $0-1.5$ years* & & & & & 0.85 & $(0.56-1.28)$ & 0.44 \\
\hline Aberration $1.5-7.4$ years* & & & & & 1.44 & $(0.96-2.17)$ & 0.08 \\
\hline \multicolumn{8}{|l|}{ Multivariate analysis $^{a}$} \\
\hline \multicolumn{8}{|l|}{$R R M 1^{b}$} \\
\hline Normal & 211 & 1.00 & Referent & & 1.00 & Referent & \\
\hline Aberration & 40 & 0.66 & $(0.43-1.03)$ & 0.07 & & & \\
\hline Aberration $0-1.5$ years* & & & & & 0.56 & $(0.32-0.99)$ & 0.05 \\
\hline Aberration $1.5-7.4$ years* & & & & & 1.72 & $(1.05-2.79)$ & 0.03 \\
\hline \multicolumn{8}{|l|}{$R R M 2 B^{C}$} \\
\hline Normal & 217 & 1.00 & Referent & & 1.00 & Referent & \\
\hline Aberration & 34 & 1.41 & $(0.88-2.23)$ & 0.15 & 1.00 & $(0.68-1.47)$ & 1.00 \\
\hline \multicolumn{8}{|l|}{$2 \mathrm{R}$} \\
\hline Normal & 184 & 1.00 & Referent & & 1.00 & Referent & \\
\hline Aberration & 67 & 0.92 & $(0.64-1.33)$ & 0.66 & & & \\
\hline Aberration 0-1.5 years* & & & & & 0.80 & $(0.52-1.22)$ & 0.30 \\
\hline Aberration 1.5-7.4 years* & & & & & 1.36 & $(0.89-2.09)$ & 0.16 \\
\hline
\end{tabular}

Abbreviations: $2 R$ aberration $R R M 1$ and/or RRM2B aberrant, $2 R$ normal $R R M 1$ and $R R M 2 B$ both normal, $C l$ confidence interval, $H R$ hazard ratio, $R R M 1$ ribonucleotide reductase $M 1$ subunit, $R R M 2 B$ ribonucleotide reductase $M 2 B$ subunit.

a Models adjusted for the effects of PAM50 status, visceral disease, stage of disease, number of metastatic sites, and performance status. Models stratified for previous chemotherapy (none, $n=70$; adjuvant, $n=86$; locally advanced or metastatic, $n=95$ ).

${ }^{b}$ Model further adjusted for RRM2B.

${ }^{\mathrm{C}}$ Model further adjusted for RRM1.

*Time-dependant variable. If nothing is mentioned the maximum follow-up is 7.4 years after randomization for OS and 6.0 years after randomization for TTP. 
Differences in methodologies, chemotherapy regimens, and cancer type do compromise the comparability of studies, and the prognostic significance of RRM1 in advanced breast cancer remains to be further elucidated.

Amplifications were the most common gene copy number variation in relation to $R R M 2 B$ observed in this study. This is in agreement with the location of $R R M 2 B$ at $8 \mathrm{q} 22.3$ which is a chromosomal region commonly characterized by DNA copy number gains $[27,36]$. Several studies have pointed out that the gain of $8 \mathrm{q}$ is a recurrent event in sporadic breast cancer with poor prognosis [36,37]. An association between RRM2B expression and increased survival has been noticed in lung and colon cancer [38-40], whereas an association with poor prognosis has been observed in esophageal cancer patients [41]. RRM2B aberrations in this study did not show any prognostic impact, in agreement with one clinical study by Uramoto et al. (2006) [42] that found no support for an association between RRM2B protein expression and survival outcome in stage I-III lung cancer patients. Hence, there was a non-significant trend that patients with $R R M 2 B$ amplifications or deletions had disease progression earlier than patients with normal $R R M 2 B$ status.

Moreover, the predictive value of RRM1 and RRM2B in relation to gemcitabine-containing versus non-gemcitabine-containing therapy has not received much attention, as only few and very small retrospective studies have compared the effect of gemcitabine with a control/gemcitabine naïve group [32]. More recently, an international phase III trial that utilized levels of RRM1 to assign lung cancer patients to a gemcitabine-containing regimen if RRM1 levels were low and a docetaxel-containing regimen if RRM1 levels were high versus a control arm of unselected chemotherapy consisting of carboplatin plus gemcitabine, did not demonstrate a survival or response rate benefit from individualizing therapy [43]. Our data did not show a significant interaction between $R R M 1$ and/ or $R R M 2 B$ copy number status and outcome from adding gemcitabine to docetaxel in terms of TTP or OS. An interesting aspect in the context of the gemcitabine-taxane chemotherapy combination could be the coexpression of RRM1 and BRCA1 previously observed in metastatic breast cancer specimens [44]. Where RRM1 low/negative expression has been connected to gemcitabine sensitivity, decreased BRCA1 expression may enhance the resistance to anti-microtubule agents [45]. Hence, the clinical specimens investigated in this study may appear suboptimal to provide results indicating an interaction between RRM1 and the clinical outcome of gemcitabine.

$R R M 2 B$ status was significantly associated with HER2 status. Almost $30 \%$ of the tumors with a $R R M 2 B$ aberration also had HER2 amplification. Several previous studies have shown a nonrandom accumulation of amplifications of different genomic regions in certain breast cancers that are considered to show an 'amplifier' phenotype $[20,27,36,46,47]$. Aberrations at the $8 \mathrm{q} 22$ locus are probably also part of a spectrum of breast carcinomas with high genomic instability and frequent amplifications. In addition, this is in agreement with $R R M 2 B$ status being significantly associated with gene expression classified intrinsic subtype, as all but one aberration were seen to accumulate in the more proliferating non-luminal A subtypes [20,21]. This is, however, in contrast to RRM1 copy number variation, which was not significantly different between the subtypes of breast cancer. A previous study by Kim et al. (2011) [48] where the expression of RRM1 protein in breast cancer samples was evaluated by immunohistochemical classification reached the same conclusion. The relatively frequent aberrations observed in this study imply that $R R M 1$ and $R R M 2 B$ are capable of contributing to breast cancer development. The aberrations were not associated suggesting that the aberrations characterize two distinct geno-subtypes with different genetic pathways in the evolution of invasive breast cancer.

The strengths of the study include data from more than $74 \%$ of the participants from a randomized trial, prospectively defined hypotheses and analysis plan, long term follow-up, biomarker analysis blinded from clinical outcome, and outcome analysis by an independent statistical core. However, the statistical power was limited due to the small population size, especially under-powering the results of the subgroup analysis. Furthermore, a potential limitation concerns the fact that the predictive value of gene aberrations is evaluated upon the primary tumor profile, although the molecular portrait could have changed pronouncedly between primary and metastatic disease $[49,50]$. Moreover, one has to consider the limitations of conclusions based on an evaluation at the genomic level only. This study focused on gene copy number changes without correlation with gene expression. Also, point mutations, not detectable by the FISH assay utilized in this study, could be of significant value [51,52], as well as several factors but genetic alterations could influence the expression and activity of the enzyme proteins, such as posttranscriptional and posttranslational regulation.

\section{Conclusions}

In summary, this study revealed the occurrence of $R R M 1$ and $R R M 2 B$ aberrations in primary breast tumor specimens. We found no support of a differential outcome according to these aberrations in advanced breast cancer patients randomized to the combination of gemcitabine and docetaxel as compared to docetaxel alone. 


\section{Additional files}

Additional file 1: Table S1. Patient demographics, disease characteristics, and prior therapy for excluded versus included patients.

Additional file 2: Table S2. Association between $R R M 1, R R M 2 B$, and $2 R$ status and patient demographics, disease characteristics, and prior therapy.

\section{Abbreviations}

2R aberration: $R R M 1$ and/or RRM $2 B$ aberrant; $2 \mathrm{R}$ normal: $R R M 1$ and $R R M 2 B$ both normal; BAC: Bacterial artificial chromosome; CEN-8: Centromeric probe for chromosome 8; CEN-11: Centromeric probe for chromosome 11; Cl: Confidence interval; D: Docetaxel; DBCG: Danish breast cancer cooperative group; ECOG: Eastern cooperative oncology group; FISH: Fluorescence in situ hybridization; FFPE: Formalin-fixed, paraffin-embedded; G: Gemcitabine; HER2: Human epidermal growth factor receptor 2; HR: Hazed ratio; OS: Overall survival; PNA: Peptide nucleic acid; RR: Response rate; RNR: Ribonucleotide reductase; RRM1: Ribonucleotide reductase M1 subunit; RRM2: Ribonucleotide reductase M2 subunit; RRM2B: Ribonucleotide reductase M2B subunit; TMA: Tissue micro array; TOP2A: DNA topoisomerase II-alpha; TTP: Time to progression.

\section{Competing interests}

The authors declare that they have no competing interests.

\section{Authors' contributions}

$K V N, B E, E B$, and CLTJ made contributions to conception and design of the study. DLN and BE provided access to clinical data on study material, and EB and CLTJ collected the tissue samples and constructed the TMAs. CLTJ performed FISH analysis and evaluation of samples. KDB and CLTJ performed the statistical analysis. All authors contributed to analysis and interpretation of data. CLTJ and KVN drafted the manuscript, and all authors contributed to the manuscript preparation and in revising the manuscript critically. All authors read and approved the final manuscript.

\section{Acknowledgements}

This work was supported by grants from the I.M. Daehnfeldt Foundation, Breast Friends, the Research Council of Herlev University Hospital, the research fund of Department of Pathology of Herlev University Hospital (Patologiafdelingens Forskningsfond), 'A.P.Møller og Hustru Chastine Mc-Kinney Møllers Fond til Lægevidenskabens Fremme', 'Grosserer M. Brogaard og Hustrus Mindefond, Odense', 'Fru Astrid Thaysens Legat for Lægevidenskabelig Grundforskning', 'Karen A. Tolstrups Fond', 'Dansk Kræftforsknings Fond', 'Beckett-Fonden', 'Carl og Ellen Hertz' Legat', 'Fabrikant Einar Willumsens Mindelegat', and 'Anita og Tage Therkelsens Fond'. Sponsors had no role in study design, data collection, data analysis, data interpretation, writing of the report, or in decision to submit for publication. We are grateful to Tine Rudbeck for technical support regarding FISH and statistician Maj-Britt Jensen for critical review of the manuscript.

\section{Author details}

${ }^{1}$ Department of Pathology, Herlev University Hospital, Copenhagen, Denmark. Danish Breast Cancer Cooperative Group (DBCG) Registry, Rigshospitalet, Copenhagen, Denmark. ${ }^{3}$ Department of Oncology, Herlev University Hospital, Copenhagen, Denmark. ${ }^{4}$ VIF, Centre for Innovation and Research, Capital Region of Denmark, Copenhagen, Denmark.

Received: 10 September 2013 Accepted: 6 November 2013 Published: 12 November 2013

\section{References}

1. Nordlund P, Reichard P: Ribonucleotide reductases. Annu Rev Biochem 2006, 75:681-706.

2. Jordan A, Reichard P: Ribonucleotide reductases. Annu Rev Biochem 1998, 67:71-98.

3. Heinemann V, Xu Y-Z, Chubb S, Sen A, Hertel LW, Grindey GB, Plunkett W: Inhibition of ribonucleotide reduction in CCRF-CEM cells by 2',2'-difluorodeoxycytidine. Mol Pharmacol 1990, 38:567-572.
4. Heinemann V, Hertel LW, Grindley GB, Plunkett W: Comparison of the cellular pharmacokinetics and toxicity of 2',2'-difluorodeoxycytidine and 1-beta-d-arabinofuranosylcytosine. Cancer Res 1988, 48:4024-4031.

5. Shao J, Zhou B, Chu B, Yen Y: Ribonucleotide reductase inhibitors and future drug design. Curr Cancer Drug Targets 2006, 6:409-431.

6. Jordheim $L P$, Séve $P$, Trédan $O$, Dumontet $C$ : The ribonucleotide reductase large subunit (RRM1) as a predictive factor in patients with cancer. Lancet Oncol 2011, 12:694-702.

7. Tooker P, Yen WC, Ng SC, Negro-Vilar A, Hermann TW: Bexarotene (LGD1069, Targretin), a selective retinoid $X$ receptor agonist, prevents and reverses gemcitabine resistance in NSCLC cells by modulating gene amplification. Cancer Res 2007, 67:4425-4433.

8. Jordheim LP, Guittet O, Lepoivre M, Galmarini CM, Dumontet C: Increased expression of the large subunit of ribonucleotide reductase is involved in resistance to gemcitabine in human mammary adenocarcinoma cells. Mol Cancer Ther 2005, 4:1268-1276.

9. Gong W, Zhang X, Wu J, Chen L, Li L, Sun J, Lv Y, Wei X, Du Y, Jin H, Dong $J$ : RRM1 expression and clinical outcome of gemcitabine-containing chemotherapy for advanced non-small-cell lung cancer: a meta-analysis. Lung Cancer 2012, 75:374-380.

10. Bepler G, Sommers KE, Cantor A, Li X, Sharma A, Williams C, Chiappori A Haura E, Antonia S, Tanvetyanon T, Simon G, Obasaju C, Robinson LA: Clinical efficacy and predictive molecular markers of neoadjuvant gemcitabine and pemetrexed in resectable non-small cell lung cancer. J Thorac Oncol 2008, 3:1112-1118.

11. Reynolds C, Obasaju C, Schell MJ, Li X, Zheng Z, Boulware D, Caton JR, Demarco LC, O'Rourke MA, Shaw Wright G, Boehm KA, Asmar L, Bromund J, Peng G, Monberg MJ, Bepler G: Randomized phase III trial of gemcitabine-based chemotherapy with in situ RRM1 and ERCC1 protein levels for response prediction in non-small-cell lung cancer. J Clin Oncol 2009, 27:5808-5815.

12. Su C, Zhou S, Zhang L, Ren S, Xu J, Zhang J, Lv M, Zhang J, Zhou C: ERCC1, RRM1 and BRCA1 mRNA expression levels and clinical outcome of advanced non-small cell lung cancer. Med Oncol 2011, 28:1411-1417.

13. Vilmar AC, Santoni-Ruqiu E, Sorensen JB: Predictive impact of RRM1 protein expression on vinorelbine efficacy in NSCLC patients randomly assigned in a chemotherapy phase III trial. Ann Oncol 2013, 24:309-314.

14. Davidson JD, Ma L, Flagella M, Geeganage S, Gelbert LM, Slapak CA: An increase in the expression of ribonucleotide reductase large subunit 1 is associated with gemcitabine resistance in non-small cell lung cancer cell lines. Cancer Res 2004, 64:3761-3766.

15. Duxbury MS, Ito H, Zinner MJ, Ashley SW, Whang EE: RNA interference targeting the M2 subunit of ribonucleotide reductase enhances pancreatic adenocarcinoma chemosensitivity to gemcitabine. Oncogene 2004, 23:1539-1548.

16. Boukovinas I, Papadaki C, Mendez P, Taron M, Mavroudis D, Koutsopoulos A, Sanchez-Ronco M, Sanchez JJ, Trypaki M, Staphopoulos E, Georgoulias V, Rosell R, Souglakos J: Tumor BRCA1, RRM1 and RRM2 mRNA expression levels and clinical response to first-line gemcitabine plus docetaxel in non-small-cell lung cancer patients. PLOS One 2008, 3:e3695.

17. Souglakos J, Boukovinas I, Taron M, Mendez P, Mavroudis D, Tripaki M, Hatzidaki D, Koutsopoulos A, Stathopoulos E, Georgoulias V, Rosell R: Ribonucleotide reductase subunits $\mathrm{M} 1$ and $\mathrm{M} 2$ mRNA expression levels and clinical outcome of lung adenocarcinoma patients treated with docetaxel/gemcitabine. Br J Cancer 2008, 98:1710-1715.

18. Sato J, Kimura T, Saito T, Anazawa T, Kenjo A, Sato Y, Tsuchiya T, Gotoh M: Gene expression analysis for predicting gemcitabine resistance in human cholangiocarcinoma. J Hepatobiliary Pancreat Sci 2011, 18:700-711.

19. Nielsen DL, Bjerre KD, Jakobsen EH, Cold S, Stenbygaard L, Sorensen PG, Kamby C, Moller S, Jorgensen CL, Andersson M: Gemcitabine plus docetaxel versus docetaxel in patients with predominantly human epidermal growth factor receptor 2-negative locally advanced or metastatic breast cancer: a randomized, phase III study by the Danish breast cancer cooperative group. J Clin Oncol 2011, 29:4748-4754.

20. Smid M, Hoes M, Sieuwerts AM, Sleijfer S, Zhang Y, Wang Y, Foekens JA, Martens JW: Patterns and incidence of chromosomal instability and their prognostic relevance in breast cancer subtypes. Breast Cancer Res Treat 2011, 128:23-30.

21. Weigman VJ, Chao HH, Shabalin AA, He X, Parker JS, Nordgard SH, Grushko T, Huo D, Nwachukwu C, Nobel A, Kristensen VN, Borresen-Dale AL, Olopade Ol, Perou CM: Basal-like Breast cancer DNA copy number losses identify genes involved in genomic instability, response to therapy, and patient survival. Breast Cancer Res Treat 2012, 133:865-880. 
22. Henriksen $\mathrm{KL}$, Rasmussen BB, Lykkesfeldt AE, Moller S, Ejlertsen B, Mouridsen $H T$ : Semi-quantitative scoring of potentially predictive markers for endocrine treatment of breast cancer: a comparison between whole sections and tissue microarrays. J Clin Pathol 2007, 60:397-404.

23. Nielsen KV, Ejlertsen B, Muller S, Moller S, Rasmussen BB, Balslev E, Laenkholm AV, Christiansen P, Mouridsen HT: Amplification of ESR1 may predict resistance to adjuvant tamoxifen in postmenopausal patients with hormone receptor positive breast cancer. Breast Cancer Res Treat 2011, 127:345-355.

24. McShane LM, Altman DG, Sauerbrei W, Taube SE, Gion M, Clark GM, Statistics Subcommittee of the NCIEWGoCD: REporting recommendations for tumour MARKer prognostic studies (REMARK). Eur J Cancer 2005, 41:1690-1696.

25. Simon RM, Paik S, Hayes DF: Use of archived specimens in evaluation of prognostic and predictive biomarkers. J Natl Cancer Inst 2009, 101:1446-1452.

26. Parker JS, Mullins M, Cheang MC, Leung S, Voduc D, Vickery T, Davies $S$, Fauron C, He X, Hu Z, Quackenbush JF, Stijleman IJ, Palazzo J, Marron JS, Nobel AB, Mardis E, Nielsen TO, Ellis MJ, Perou CM, Bernard PS: Supervised risk predictor of breast cancer based on intrinsic subtypes. J Clin Oncol 2009, 27:1160-1167.

27. Saito S, Morita K, Hirano T: High frequency of common DNA copy number abnormalities detected by bacterial artificial chromosome array comparative genomic hybridization in 24 breast cancer cell lines. Hum Cell 2009, 22:1-10.

28. Fridlyand J, Snijders AM, YIstra B, Li H, Olshen A, Segraves R, Dairkee S, Tokuyasu T, Ljung BM, Jain AN, McLennan J, Ziegler J, Chin K, Devries S, Feiler H, Gray JW, Waldman F, Pinkel D, Albertson DG: Breast tumor copy number aberration phenotypes and genomic instability. BMC Cancer 2006, 6:96

29. Albertson DG, Collins C, McCormick F, Gray JW: Chromosome aberrations in solid tumors. Nat Genet 2003, 34:369-376.

30. Winqvist R, Hampton GM, Mannermaa A, Blanco G, Alavaikko M, Kiviniemi $H$, Taskinen PJ, Evans GA, Wright FA, Newsham I, Cavenee WK: Loss of heterozygosity for chromosome 11 in primary human breats tumors is assocaited with poor survival after metastasis. Cancer Res 1995, 55:2660-2664

31. Bepler G, Gercia-Blanco MA: Three tumor-suppressor regions on chromosome $11 \mathrm{p}$ identified by high-resolution deletion mapping in human non-small-cell lung cancer. Proc Natl Acad Sci U S A 1994, 91:5513-5517.

32. Akita H, Zheng Z, Takeda Y, Kim C, Kittaka N, Kobayashi S, Marubashi S, Takemasa I, Nagano H, Dono K, Nakamori S, Monden M, Mori M, Doki Y, Bepler G: Significance of RRM1 and ERCC1 expression in resectable pancreatic adenocarcinoma. Oncogene 2009, 28:2903-2909.

33. Bepler G, Sharma S, Cantor A, Gautam A, Haura E, Simon G, Sharma A, Sommers E, Robinson L: RRM1 and PTEN as prognostic parameters for overall and disease-free survival in patients with non-small-cell lung cancer. J Clin Oncol 2004, 22:1878-1885.

34. Harshman LC, Bepler G, Zheng Z, Higgins JP, Allen Gl, Srinivas S: Ribonucleotide reductase subunit $\mathrm{M} 1$ expression in resectable, muscle-invasive urothelial cancer correlates with survival in younger patients. BJU Int 2010, 106:1805-1811.

35. Zheng Z, Chen T, Li X, Haura E, Sharma A, Bepler G: DNA synthesis and repair genes RRM1 and ERCC1 in lung cancer. N Engl I Med 2007, 356:800-808.

36. Rennstam K, Ahlstedt-Soini M, Baldetrop B, Bendahl P-O, Borg A, Karhu R, Tanner M, Tirkkonen M, Isola J: Patterns of chromosomal imbalances defines subgroups of breast cancer with distinct clinical fetures and prognosis: a study of 305 tumors by compartive genomic hybridization Cancer Res 2003, 63:8861-8868.

37. Blegen H, Will JS, Ghadimi M, Nash H-P, Zetterberg A, Auer G, Ried T: DNA amplifications and aneuploidy, high proliferative activity and impaired cell cycle control characterize breast carcinomas with poor prognosis. Anal Cell Pathol 2003, 25:103-114.

38. Hsu N-Y, Wu J-Y, Liu X, Yen Y, Chen C-Y, Chou M-C, Lin C-H, Lee H, Cheng Y-W: Expression status of ribonucleotide reductase small subunits hRRM2/p53R2 as prognostic biomarkers in stage I and II non-small cell lung cancer. Anticancer Res 2011, 31:3475.

39. Hsu NY, Wu JY, Liu X, Yen Y, Chen C-Y, Chou M-C, Lee H, Cheng Y-W: p53R2 expression as a prognostic biomarker in early stage non-small cell lung cancer. Oncology Lett 2010, 1:609.
40. Liu X, Lai L, Wang X, Xue L, Leora S, Wu J, Hu S, Zhang K, Kuo ML, Zhou L, Zhang H, Wang Y, Wang Y, Zhou B, Nelson RA, Zheng S, Zhang S, Chu P, Yen $Y$ : Ribonucleotide reductase small subunit M2B prognoses better survival in colorectal cancer. Cancer Res 2011, 71:3202-3213.

41. Okumura H, Natsugoe S, Yokomakura N, Kita Y, Matsumoto M, Uchikado Y, Setoyama T, Owaki T, Ishigami S, Aikou T: Expression of p53R2 is related to prognosis in patients with esophageal squamous cell carcinoma. Clin Cancer Res 2006, 12:3740-3745.

42. Uramoto HSK, Oyama T, Hanagiri T, Yasumoto K: p53R2, p53 inducible ribonucleotide reductase gene, correlated with tumor progression of non-small cell lung cancer. Anticancer Res 2006, 26:983-988.

43. Bepler G, Williams C, Schell MJ, Chen W, Zheng Z, Simon G, Gadgeel S, Zhao X, Scheiber F, Brahmer J, Chiappori A, Tanvetyanon T, Pinder-Schenck M, Gray J, Haure E, Antonia S, Fischer JR: Randomized international phase III trial of ERCC1 and RRM1 expression-based chemotherapy versus gemcitabine/carboplatin in advanced non-small-cell lung cancer. J Clin Oncol 2013, 31:2404-2412.

44. Metro G, Zheng Z, Fabi A, Schell M, Antoniani B, Mottolese M, Monteiro AN, Vici P, Lara Rivera S, Boulware D, Cognetti F, Bepler G: In situ protein expression of RRM1, ERCC1, and BRCA1 in metastatic breast cancer patients treated with gemcitabine-based chemotherapy. Cancer Invest 2010, 28:172-180.

45. Chabalier C, Lamare C, Racca C, Privat M, Valette A, Larminat E: BRCA1 downregulation leads to premature inactivation of spindle checkpoint and confers paclitaxel resistance. Cell Cycle 2006, 5:1001-1007.

46. Albertson DG: Gene amplification in cancer. Trends Genet 2006 22:447-455.

47. Melchor L, Alvarez S, Honrado E, Palacios J, Barroso A, Diez O, Osorio A, Benitez J: The accumulation of specific amplifications characterizes two different genomic pathways of evolution of familial breast tumors. Clin Cancer Res 2005, 11:8577-8584.

48. Kim D, Jung W, Koo JS: The expression of ERCC1, RRM1, and BRCA1 in breast cancer according to the immunohistochemical phenotypes. J Korean Med Sci 2011, 26:352-359.

49. Chang HJ, Han SW, Oh DY, Im SA, Jeon YK, Park IA, Han W, Noh DY, Bang YJ, Kim TY: Discordant human epidermal growth factor receptor 2 and hormone receptor status in primary and metastatic breast cancer and response to trastuzumab. Jpn J Clin Oncol 2011, 41:593-599.

50. Xiao C, Gong Y, Han EY, Gonzalez-Angulo AM, Sneige N: Stability of HER2-positive status in breast carcinoma: a comparison between primary and paired metastatic tumors with regard to the possible impact of intervening trastuzumab treatment. Ann Oncol 2011, 22:1547-1553.

51. Bepler G, Zheng Z, Gautam A, Sharma S, Cantor A, Sharma A, Cress WD, Kim YC, Rosell R, McBride C, Robinson L, Sommers E, Haura E: Ribonucleotide reductase $\mathrm{M} 1$ gene promoter activity, polymorphisms, population frequencies, and clinical relevance. Lung Cancer 2005, 47:183-192.

52. Dong S, Guo A-L, Chen Z-H, Wang Z, Zhang X-C, Huang Y, Xie Z, Yan H-H, Cheng H, WU Y-L: RRM1 single nucleotide polymorphism -37C- $>$ A correlates with progression-free survival in NSCLC patients after gemcitabine-based chemotherapy. J Hematol Oncol 2010, 3:10.

doi:10.1186/1471-2407-13-541

Cite this article as: Jørgensen et al:: Gene aberrations of RRM1 and $R R M 2 B$ and outcome of advanced breast cancer after treatment with docetaxel with or without gemcitabine. BMC Cancer 2013 13:541.

\section{Submit your next manuscript to BioMed Central and take full advantage of:}

- Convenient online submission

- Thorough peer review

- No space constraints or color figure charges

- Immediate publication on acceptance

- Inclusion in PubMed, CAS, Scopus and Google Scholar

- Research which is freely available for redistribution 